\title{
Neonatal Severe Hyperparathyroidism: A Fatal Case
}

\author{
Gawri Abeynayake $^{1^{*}}$, Eresha Jasinge ${ }^{2}$, Ramya Ediriweera ${ }^{3}$ and Michael A. Levine ${ }^{4}$ \\ ${ }^{1}$ MD, Senior Registrar, Department of Chemical Pathology, National Hospital of Sri Lanka, Colombo 01000, Sri Lanka \\ ${ }^{2} \mathrm{MD}$, Consultant Chemical Pathologist, Lady Ridgeway Hospital for Children, Colombo 00800, Sri Lanka, \\ ${ }^{3}$ MD, Consultant Pediatrician, Lady Ridgeway Hospital for Children, Colombo 00800, Sri Lanka \\ ${ }^{4}$ MD,FAAP,FACP,MACE, Chief, Division of Endocrinology and Diabetes, Director, Centre for Bone Health, Children's \\ Hospital of Philadelphia, 3401 Civic Center Blvd., Suite 11NW 30, Philadelphia, PA, 19104, USA
}

Received: December 16, 2017; Accepted: January 08, 2018; Published: January 15, 2018

*Corresponding author: Gawri P.N. Abeynayake, MD, Senior Registrar, Department of Chemical Pathology, National Hospital of Sri Lanka, Colombo 01000 , Sri Lanka; Tel: +94718679919; E-mail address: Gawri_abey@yahoo.com

\section{Abstract}

Background: Neonatal severe primary hyperparathyroidism (NSHPT) is a rare disorder that is usually caused by homozygous inactivating mutations in the CASR gene encoding the calcium sensing receptor (CaSR). Although parathyroidectomy is the treatment of choice, bisphosphonates and calcimimetics such as cinacalcet have been used to improve hypercalcemia prior to or in lieu of surgery.

Case Presentation : A female neonate born to consanguineous parents with paternal history of renal calculi was admitted at 1 month of age for suspected respiratory distress due to aspiration pneumonia. Laboratory testing revealed severe hypercalcaemia, elevated parathyroid hormone, hypophosphataemia, increased alkaline phosphatase and low fractional excretion of calcium (FeCA) of 0.01. Radiographs demonstrated osteopaenia. Treatment was initiated with pamidronate after completion of investigations, which reduced serum calcium level. Nevertheless, the baby expired. Genetic analyses revealed homozygosity for a novel CASR gene terminator mutation in exon 4 (c.679 C > T, p.227 R $>$ X). The parents refused genetic studies.

Conclusion: his neonate with respiratory distress, osteopaenia, severe hypercalcaemia and hyperparathyroidism was found to have a novel omozygous mutation of CASR gene, consistent with the diagnosis of NSHPT.

Keywords: Hypercalcaemia; neonate; calcium sensing receptor; neonatal severe hyperparathyroidism; familial benign hypercalcemic; hypocalcaemia

Abbreviations: ALP: Alkaline Phosphatase; CASR: Calcium Sensing Receptor; FeCA: Fractional Excretion Of Calcium; FHH : Familial benign Hypercalcaemic Hypocalciuria; NSHPT : Neonatal Severe Hyperparathyroidism; PTH : Parathyroid Hormone

\section{Introduction}

Levels of extracellular ionized calcium are tightly regulated, principally through the action of parathyroid hormone (PTH), which is secreted from parathyroid cells in response to signals from membrane-bound calcium sensing receptors (CaSR). Genetic mutations that impair calcium sensing result in mild to moderate increases in PTH, hypercalcemia, and Hypocalciuria, a condition termed familial benign Hypercalcaemic Hypocalciuria (FHH). FHH is usually an autosomal dominant condition due to heterozygous loss-of-function mutations in the CASR gene [1-3], but autosomal recessive inheritance may occur as well [4]. FHH also can result from inactivating mutations in the GNA11 and AP2S1 genes that encode additional proteins that are required for CaSR signaling [5,6]. By contrast to FHH, biallelic inactivating CASR mutations are associated with life-threatening neonatal severe primary hyperparathyroidism (NSHPT) [1-3], which results in generalized skeletal demineralization, neurological disabilities, constipation, failure to thrive, respiratory distress and irritability [7]. In the absence of early recognition and urgent intervention, NSHPT is usually a fatal condition. We report the first case of a newborn girl diagnosed with NSHPT in Sri Lanka and found to have a novel homozygous inactivating mutation of the CASR gene.

\section{Case Presentation}

The proband was a female infant who was born full term to consanguineous parents. The baby was delivered via caesarean section due to pregnancy induced hypertension, and presented at 1 month of age with cough, dyspnea, and poor intake of infant formula. The baby was admitted to hospital for evaluation; she appeared ill and her length and weight were below -2SD with microcephaly. The baby was intubated and transferred to medical intensive care unit. Her chest X-revealed inflammatory shadows, but the most striking feature noted was osteopaenia. Laboratory analysis revealed severe hypercalcemia (4.64 mmol/L), hypophosphatemia $(0.65 \mathrm{mmol} / \mathrm{L})$, an increased serum ALP 
(1782 U/L) and a very low urinary calcium : creatinin clearance ratio (0.01). Her plasma intact PTH was remarkably high $(1142$ $\mathrm{pg} / \mathrm{mL}$ ) but ultra-sound scan of neck did not reveal a parathyroid gland abnormality. Her echocardiography showed biventricular hypertrophy with no other abnormalities. An ultrasound scan of the abdomen was normal and there were no renal calcifications. She was treated with intravenous pamidronate $(1 \mathrm{mg} / \mathrm{kg})$ in preparation for parathyroid surgery. Although pamidronate treatment reduced serum the calcium level significantly, the baby expired due to respiratory arrest. A diagnosis of NSHPT was made, and after informed assent, DNA was extracted from peripheral blood mononuclear cells and the CASR gene was analyzed for mutations as previously described [4]. Molecular studies revealed that a patient was homozygous for a novel terminator mutation in exon 4, c.679 C>T, p.227 R>X, (Figure 1). The consanguineous parents (Figure 2) and one sister (IV-2) have normal calcium levels, while one other sister (IV-3) has a slightly elevated serum calcium level (Table 1). A brother has a history of rickets, likely due to vitamin D and calcium deficiency. Her father and paternal two uncles have histories of renal stones. There is a past history of infantile death of uncertain cause in a brother at the age of 7 months. The rest of the family refused CASR mutation testing.

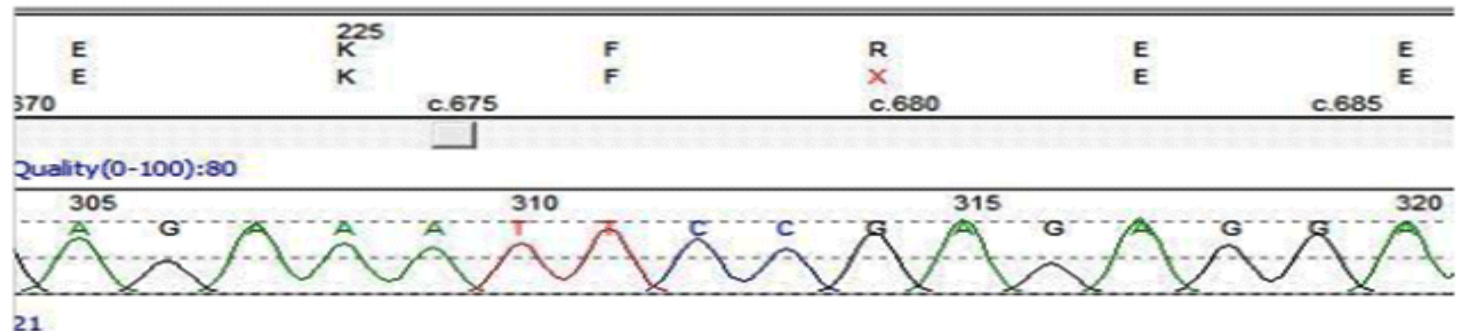

21

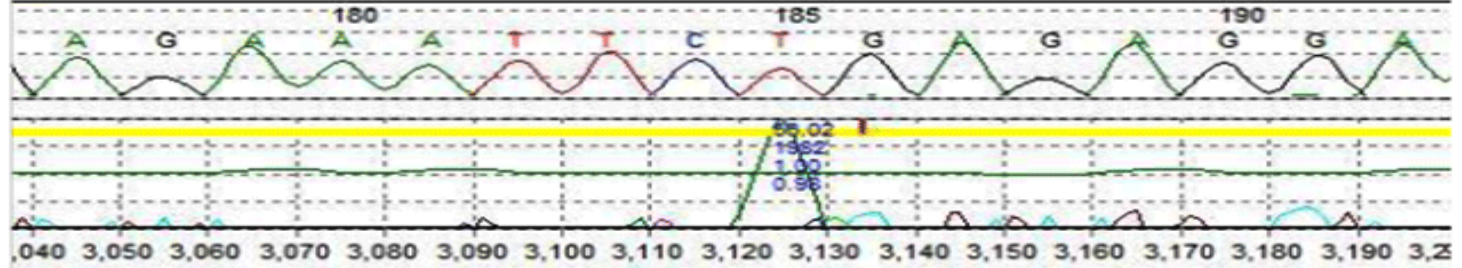

Figure 1: Homozygous novel inactivating mutation in CASR, terminator mutation in exon 4, c.679 C>T, p.227 R>X (lower panel) compared to normal CASR sequence in the upper panel

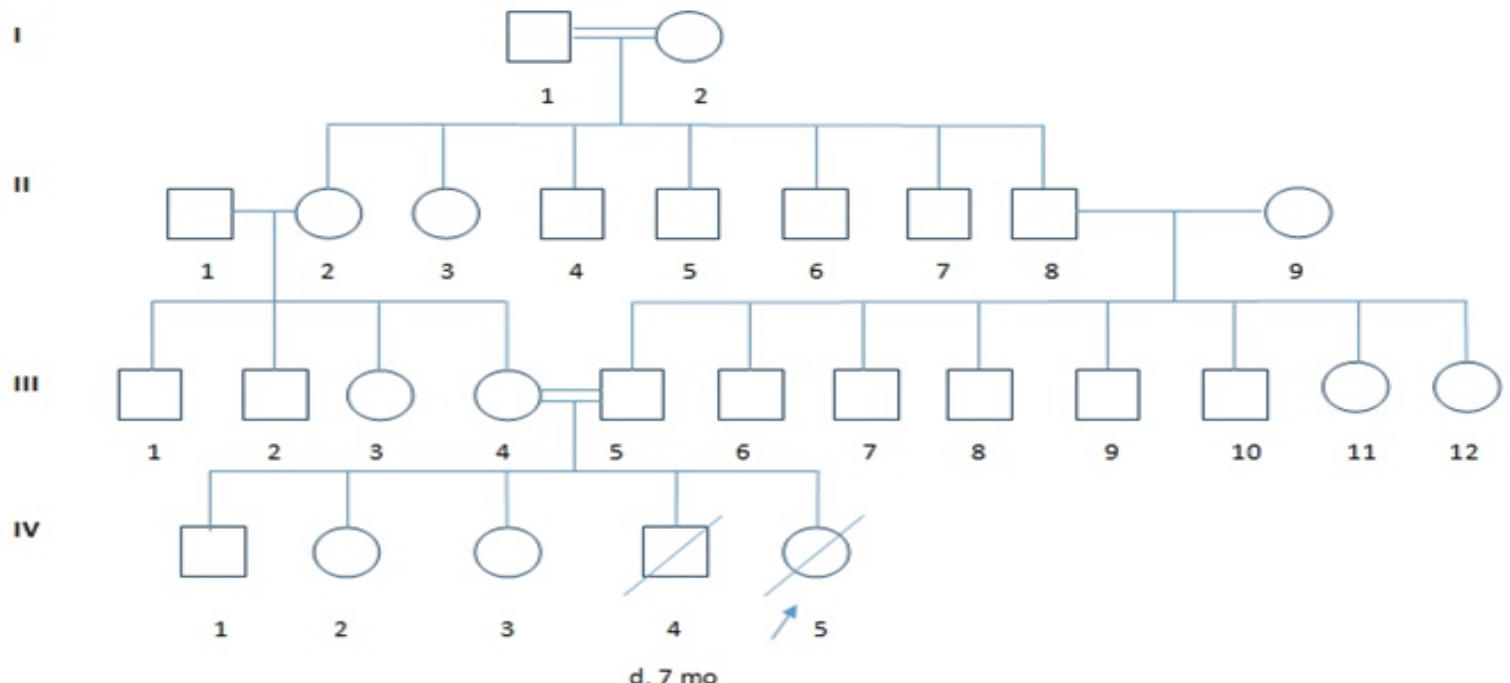

Figure 2: Family pedigree. The arrow indicates the proband and the double horizontal line indicates parental consanguinity. 


\begin{tabular}{|c|c|c|c|c|c|}
\hline Laboratory Test & Father & Mother & Brother IV-1 & Sister IV-2 & Sister IV-3 \\
\hline $\begin{array}{l}\text { Serum Calcium Reference range } \\
\quad(\mathrm{mmol} / \mathrm{L})(2.20-2.70)\end{array}$ & 2.68 & 2.6 & 1.49 & 2.59 & 2.72 \\
\hline $\begin{array}{c}\text { Serum Phosphate Reference } \\
\text { range }(\mathrm{mmol} / \mathrm{L}) \\
<2 \text { yrs }(1.45-2.16) \\
2-12 \operatorname{yrs}(1.45-1.78)>12 \\
\operatorname{yrs}(0.87-1.45)\end{array}$ & 1.05 & 0.97 & 1.44 & 1.45 & 1.37 \\
\hline $\begin{array}{c}\text { Serum ALP Reference } \\
\text { ranges(U/L) } \\
\text { children }(80-480) \\
\text { Adults }(100-360)\end{array}$ & 127 & 196 & 4296 & 806 & 540 \\
\hline Fraction excretion of Calcium & 0.004 & 0.002 & 0.002 & 0.01 & 0.002 \\
\hline
\end{tabular}

\section{Discussion}

To our knowledge this is the first report of NSHPT in Sri Lanka confirmed with genetic studies. NSHPT is an uncommon disorder that usually results from biallelic loss of function mutations in CASR gene although heterozygous dominant inhibitor mutations have also been reported [8]. Loss of calcium sensing will lead to parathyroid hyperplasia and increased PTH secretion and decreased renal excretion of calcium. These babies present with failure to thrive, hypotonia, respiratory distress, constipation and bone abnormalities such as demineralisation, rib cage deformity, subperiosteal erosions and metaphyseal widening of long bones[7]. In the case we report here, the baby had failure to thrive, hypotonia, osteopaenia and was hospitalised due to respiratory distress. The differential diagnosis of hypercalcemia in babies this age would include idiopathic infantile hypercalcaemia, Williams syndrome, vitamin D intoxication, IMAGE, infantile hypophosphatasia and $\mathrm{FHH}$, but in none of these conditions is the PTH so elevated and the urinary calcium so low as in NSHPT. FHH, NSHPT and antenatal Bartter syndrome type 1 due to SLC12A1 [9] are the most common causes of PTH dependent hypercalcaemia in this young age group and the very low FeCA and clinical severity strongly favoured NSHPT. On the other hand CASR mutation testing including functional analysis will provide confirmatory evidence in differentiating hypercalcaemic status and it also helps in guiding the treatment [10]. Unfortunately, the baby expired and the diagnosis of NSHPT was confirmed post mortem by genetic studies. Review of the family suggests the parents, who are consanguineous, and the other children are heterozygous for the p.227 $\mathrm{R}>\mathrm{X}$ mutation, but the rest of the family would not agree to undergo testing. Interestingly, the father has a history of renal stones, but the type is unknown. Renal stones have previously been reported in patients with FHH, and are often urate $[11,12]$.

In NSHPT, medical management is inadequate and total parathyroidectomy is the treatment of choice and it is effective in most cases [13]. Intravenous bisphosphonates such as pamidronate have often been used in neonates to treat severe hypercalcaemia until surgery could be performed. The calcimimetic cinacalcet has been used successfully in several cases of NSHPT in which a wild type CaSR was present or in which abnormal CaSRs were able to respond [14]. In the case we present here the terminator mutation would predict the absence of any CaSRs on the cell surface, and one would not expect any response from calcimimetic therapy.

\section{Conclusion}

In conclusion, this case clearly illustrates, although NSHPT is a rare disease, it should be considered in differential diagnosis of neonatal hypercalcemia as prompt diagnosis and surgical intervention will be life-saving.

\section{Acknowledgement}

Sources of support

GPNA` acquired relevant clinical information and wrote the first draft of the manuscript

EJ conceived of the case report, supervised and assisted in editing of the manuscript

RE supervised the work MAL edited and finalized the manuscript .

\section{References}

1. Hendy GN, Guarnieri V, Canaff L. Calcium-sensing receptor and associated diseases. Progress in molecular biology and translational science. 2009;89:31-95. Doi: 10.1016/S1877-1173(09)89003-0

2. Ward BK, Magno AL, Walsh JP, Ratajczak T. The role of the calcium-sensing receptor in human disease. Clinical biochemistry. 2012;45(12):943-953. Doi: 10.1016/j.clinbiochem.2012.03.034

3. Doyle DA. Hyperparathyroidism. In Kliegman RM, Behrman RE, Schor NF, St Geme III JW, editors. Nelson Textbook of Paediatrics. 20 ed. USA; Elsevier: 2015.

4. Lietman SA, Tenenbaum-Rakover Y, Jap TS, et al. A novel loss-offunction mutation, Gln459Arg, of the calcium-sensing receptor gene associated with apparent autosomal recessive inheritance of familial 
hypocalciuric hypercalcemia. The Journal of clinical endocrinology and metabolism. 2009;94(11):4372-4379. Doi: 10.1210/jc.20082484

5. Nesbit MA, Hannan FM, Howles SA, et al. Mutations affecting Gprotein subunit alpha11 in hypercalcemia and hypocalcemia. The New England journal of medicine. 2013;368(26):2476-2486. Doi: 10.1056/NEJMoa1300253

6. Nesbit MA, Hannan FM, Howles SA, et al. Mutations in AP2S1 cause familial hypocalciuric hypercalcemia type 3. Nature genetics. 2013;45(1):93-97. Doi: 10.1038/ng.2492

7. Rodd C, Goodyer P. Hypercalcemia of the newborn: etiology, evaluation, and management. Pediatric nephrology (Berlin, Germany). 1999;13(6):542-547.

8. Egbuna OI, Brown EM. Hypercalcaemic and hypocalcaemic conditions due to calcium-sensing receptor mutations. Best practice \& research Clinical rheumatology. 2008;22(1):129-148. Doi: 10.1016/j. berh.2007.11.006
9. Li D, Tian L, Hou C, kin CE, Hakonarson H, Levine MA. Association of Mutations in SLC12A1 Encoding the NKCC2 Cotransporter With Neonatal Primary Hyperparathyroidism. The Journal of clinical endocrinology and metabolism. 2016;101(5):2196-2200. Doi: $10.1210 / j \mathrm{jc} .2016-1211$

10. Reddy M, Tanday R, Feeny C, Darko D, Hox J, Hadjiminas D. Renal calculi as a presenting feature in a patient with familial hypocalciuric hypercalcaemia (FHH).. Endocrine Abstracts 2012;28:P80.

11. Marx SJ, Spiegel AM, Brown EM, et al. Family studies in patients with primary parathyroid hyperplasia. The American journal of medicine. 1977;62(5):698-706. Doi: 10.1016/0002-9343(77)90873-7

12. Mallet E. Primary Hyperparathyroidism in Neonates and Childhood. Hormone Research in Paediatrics. 2008;69(3):180-188. Doi: $10.1159 / 000112592$

13. Wilhelm-Bals A, Parvex P, Magdelaine C, Girardin E. Successful Use of Bisphosphonate and Calcimimetic in Neonatal Severe Primary Hyperparathyroidism. Pediatrics. 2012;129(3):e812-e816. Doi: 10.1542/peds.2011-0128 